\title{
La transmisión textual de El robo de las sabinas en el manuscrito apógrafo Tea 1-60-13 de la Biblioteca Histórica de Madrid*
}

\author{
IVÁn Gómez CABALleRO \\ Universidad de Castilla-La Mancha
}

Resumen: El presente trabajo trata de dilucidar la transmisión textual de El robo de las sabinas en el manuscrito apógrafo Tea 1-60-13 de la Biblioteca Histórica de Madrid, del que hemos prescindido en nuestra edición crítica, por sus peculiaridades innovadoras y también por estar alejado en el tiempo respecto al codex optimus. Sin embargo, consideramos que no hay que desmerecer por ello su estudio, ya que aporta ciertas pistas sobre cómo pudo ser la puesta en escena de esta comedia en colaboración a finales del siglo xVIII.

Palabras clave: El robo de las sabinas; transmisión textual; Biblioteca Histórica de Madrid; manuscrito; teatro.

\section{El robo de las sabinas' textual transmission in the apograph manuscript Tea 1-60-13 in the Historical Library of Madrid}

\begin{abstract}
The present work tries to study El robo de las sabinas' textual transmission in the apograph manuscript Tea 1-60-13 in the Historical Library of Madrid, which, due to its innovative peculiarities and also because it is far away in time with the codex optimus, we have left it out in our critical edition. However, we consider that its study should not be devalued for this reason, because it provides certain clues about how the staging of this comedy in collaboration could have been at the end of the $18^{\text {th }}$ century.

Keywords: El robo de las sabinas; textual transmission; Historical Madrid's Library; manuscript; theatre.
\end{abstract}

\footnotetext{
Este trabajo ha sido financiado gracias a una beca de iniciación a la investigación para estudiantes de másteres universitarios oficiales, cofinanciada por el Banco Santander y por la Universidad de Castilla-La Mancha durante el curso 2020/2021 y dirigida por Rafael González Cañal, a quien le agradezco las largas sesiones de tutoría sobre ecdótica.
} 


\section{Introducción}

1 robo de las sabinas es una comedia en colaboración de la que, hasta hace muy poco, no teníamos una edición crítica. ${ }^{1}$ Así, forma parte del conjunto de comedias en colaboración de Francisco de Rojas Zorrilla (Alviti y García González, 2015), si bien presenta problemas de autoría (González Cañal, 2017: 115-116), puesto que todas las ediciones de la obra de los siglos XVII y XVIII que nos han llegado adjudican la obra a Juan Coello y Arias. Por otra parte, los catálogos bibliográficos de los siglos XVIII y XIX, entre ellos los de Juan Isidro Fajardo (1717), de Francisco Medel del Castillo (1735), de Vicente García de la Huerta (1785) y de Cayetano Alberto de la Barrera y Leirado (1860) no recogen que sea una comedia colaborada por tres ingenios. Sin embargo, Emilio Cotarelo y Mori (1911: 213-214) aporta una noticia de febrero de 1637 en la que se afirma que también participaron su hermano Antonio Coello y el dramaturgo toledano Francisco de Rojas Zorrilla:

a la noche se representó la comedia de El robo de las sabinas por los romanos de los tres ingenios clásicos, don Francisco de Rojas, don Juan y don Antonio Coello y la representó Tomás Fernández, adornándola de loa, nuevos bailes, gracioso entremés y muchas galas.

Rafael González Cañal, Germán Vega García-Luengos y Ubaldo Cerezo Rubio (2007) aportan en la Bibliografía de Francisco de Rojas Zorrilla la recensio de las diversas ediciones de El robo de las sabinas. Por tanto, tenemos una edición impresa incluida en la Parte IX de comedias nuevas escogidas de Gregorio Rodríguez (E1), otras tres sueltas $(S 1, S 2, S 3)$ y dos manuscritos apógrafos de finales del siglo XVIII $(M 1, M 2)$ :

En Parte IX de comedias nuevas escogidas..., Madrid, Gregorio

E1

Rodríguez, a costa de Juan S. Vicente, 1685.

[González Cañal, Cerezo y Vega, 2007: núm. 722].

Ejemplar utilizado: Madrid, BNE, TI/119/11.

\footnotetext{
Cfr. Rojas Zorrilla (2007, 2009, 2011a, 2011b, 2014, 2017, 2018, 2021).
} 
S1

El robo de las sabinas, s.l., s.i., s.a.

Ejemplar utilizado: Madrid, BNE, T/ 55321-29.

El robo de las sabinas, Madrid, Antonio Sanz, 1754.

S2 [González Cañal, Cerezo y Vega, 2007: núm. 724].

Ejemplar utilizado: Madrid, BHM, C 18559-3.

El robo de las sabinas, Sevilla, Manuel Nicolás Vázquez, s.a.

S3 [González Cañal, Cerezo y Vega, 2007: núm. 723].

Ejemplar utilizado: Santander, BMP, 31193.

M1

El robo de las sabinas, Madrid, BHM, ms. Tea 1-60-13, A.

[González Cañal, Cerezo y Vega, 2007: núm. 720].

$\mathrm{M} 2^{1}$

El robo de las sabinas, Madrid, BHM, ms. Tea 1-60-13, B.

[González Cañal, Cerezo y Vega, 2007: núm. 721].

Nuestro trabajo pretende, por tanto, analizar la transmisión textual de la edición $M 1$ de El robo de las sabinas desde la crítica textual neolachmanianna ${ }^{2}$, y los datos escenográficos que aporta a partir de las innovaciones y supresiones textuales desde una perspectiva semiótica. En §2 estudiamos su estructura, las fechas en que fue redactado y sus circunstancias; en \$3, la transmisión textual de las ediciones E1,S1, S2 y S3 que nos servirá para pivotar en $\$ 4$ la filiación textual de M1. Por último, en \$5 exponemos las conclusiones de nuestro estudio, por un lado, en el ámbito ecdótico, en el que trazamos el stemma codicum, y por otro, en el escenográfico, en donde presentamos las peculiaridades de la representación teatral dieciochesca.

\section{Consideraciones sobre la edición M1: materialidad y estructura}

La edición M1 es un manuscrito apógrafo con letra del siglo xvIII que se terminó de redactar el 2 julio de 1763, como indica el colofón de la tercera jornada. Consta de 82 folios numerados a lápiz dispuestos en 3 apuntes que

2 Ver Blecua Perdices (1983) y Pérez Priego (1997) para la aplicación de esta metodología ecdótica. 
se corresponden con cada una de las jornadas de El robo de las sabinas, de modo que 30 hojas corresponden a la primera; 24, a la segunda y, finalmente, 28 a la tercera:

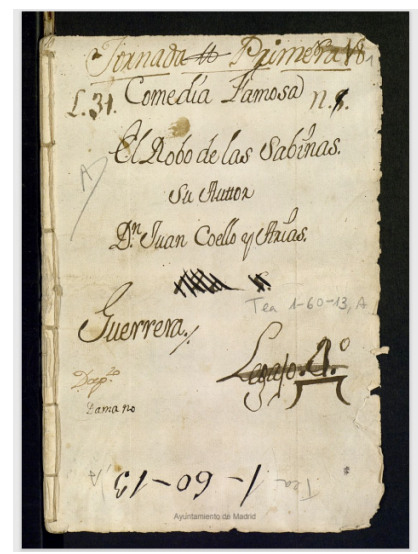

Imagen I. Portada del manuscrito apógrafo Tea 1-60-13 de la Biblioteca Histórica de Madrid.

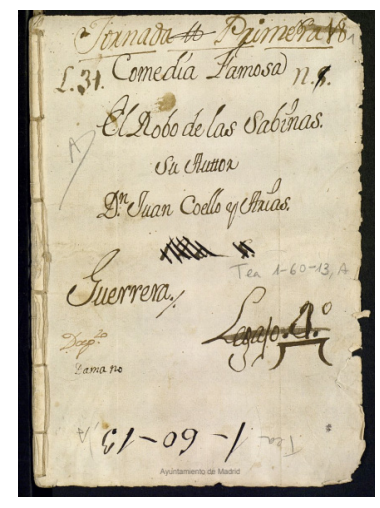

Imagen II. Portada de la primera jornada (30 h.).

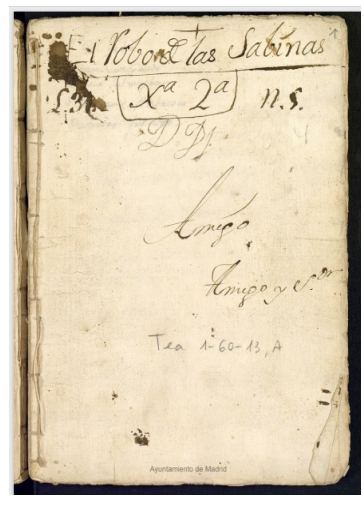

Imagen III. Portada de la segunda jornada $(24 h$.$) .$

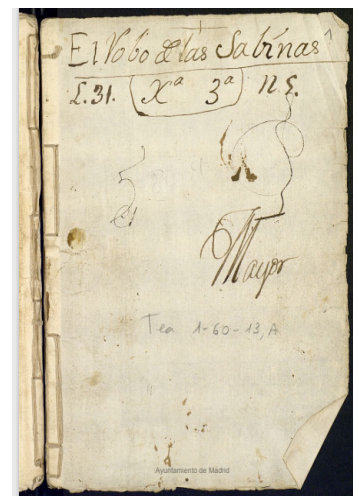

Imagen IV. Portada de la tercera jornada $(28 \mathrm{~h}$.).

En los folios finales de M1, podemos leer: «A veinte de julio de 1763. / Cabe esta comedia intitulada / El robo de las sabinas al Fiscal / Cuéllar y con lo que espero, traiga / [rúbrica ilegible]. / Señor, / dando Vuestra Majestad su licencia, puede representarse esta / comedia de El robo de las sabinas salvo el 13 de / julio del 63. / [rúbrica ilegible]. / A 15 de julio de 1763/ [rúbrica ilegible]. / Madrid y julio 30 de 1763. / [rúbrica ilegible]». Por tanto, M1 data de 1763 y su representación pudo tener lugar justo después, tras la aprobación de esta licencia. 


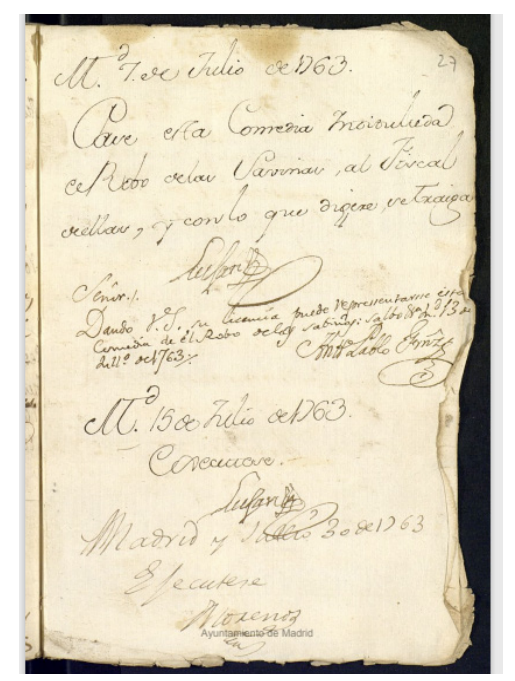

Imagen $V$. Último folio del manuscrito apógrafo Tea 1-60-13 de la Biblioteca Histórica de Madrid.

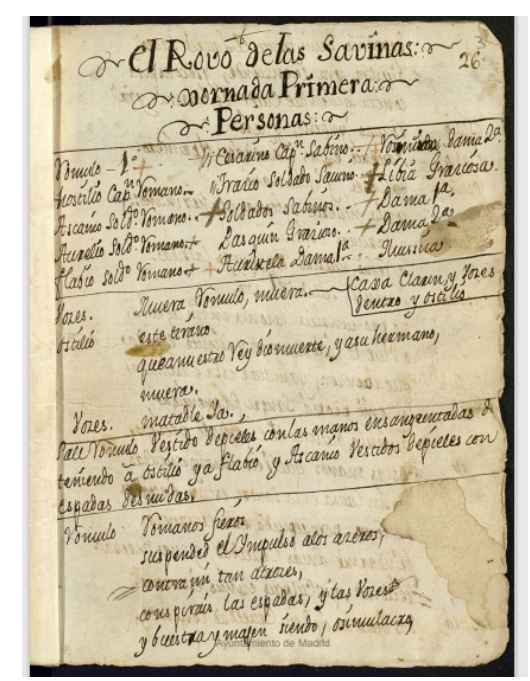

Imagen VI. Dramatis personae del manuscrito apógrafo Tea 1-60-13 de la Biblioteca Histórica de Madrid.

Curiosamente, en $M 1$ encontramos también varias tachaduras, que, en ningún caso son variantes separativas de $E 1, S 1, S 2$ y $S 3$, puesto que en todos los ejemplos se inserta justo encima la vera lectio: «entrar» (v. 75, I, h. 24v), «me» (v. 79, I, h. 24v), «la» (v. 98, I, h. 24r), «nace» (v. 106, I, h. 24r), «breve» (v. 259, I,h. 19v), «arrepientes» (v. 261, I, h. 19v), «me tienen» (v. 279, I, h. 19r), «metiesen» (v. 331, I, h. 17v), «conoces» (v. 426, I, h. 15r), «sosiega» (v. 438, I, h. 15r), «ave» (v. 442, I, 14v), «tan trocada» (v. 494, I, h. 13r), «alivio» (v. 565, I, 11r), «horror» (v. 635, 9v), «alivio» (v. 739, I, 6v), «igualmente» (v. 748, I, 6v), «aprecio» (v. 806, I, 5r), «de qué sirve» (v. 943, I, 1v), «le fie mi vida» (v. 973, II, 18r), «mucho» (v. 1033, II, 16v), «edad» (v. 1128, II, 14v), «mansamente» (v. 1131, II, 14v), «adbitrio -corrida lloro-» (v. 1163, II, 13v), «miró» (v. 1173, II, 13v), «mi» (v. 1200, II, 13r), «comides» (v. 1233, II, 12r), «tan recto» (v. 1251, II, 11v), «mi rey en fin» (v. 1288, II, 10v), «Baco» (v. 1324, II, 10r), «ruego» (v. 1337, II, 9v), «porque no se ha de guiar» (v. 1399, II, 8r), «haber» (v. 1409, II, $7 \mathrm{v})$, «conciertan» (v. 1516, II, 5r), «muero» (v. 1844, III, 18r), «entonces» (v. 1858, III, 18r), «suele» (v. 1886, III, 18r), «bebo» (v. 1936, III, 17r), «unas» (v. 2027, III, 14v), «inunda» (v. 2040, III, 14r), «amor» (v. 2216, III, 10r), «hice» (v. 2230, III, 9v) y, por, último, «con» y «doy» (v. 2293, III, 8r). Este fenómeno puede indicar dos posibilidades: bien la inseguridad del copista, bien la rapi- 
dez en la que copia el texto, que produce varios errores que tiene que tachar y reescribir encima.

\section{La transmisión textual de las ediciones E1, S1, S2 y S3}

Las variantes coniunctivi entre E1-S1 y S2-S3 transmitidas en 65, 118, 308, $338,362,364,366,398,403,405,415,432,456,588,599$, +726, 900+, 950, 1001, 1262, 1268, 1424, 1604+, 1607, 1930, 1993, 2002 2213, 2243, 2315, 2360, 2480 у 2486 presuponen necesariamente la existencia de las familias $\alpha$ y $\beta$ : la primera está formada por E1 y $S 1$ y la segunda, por $S 2$ y $S 3$. En la familia, $\alpha$ existen errores separativi, a su vez, entre E1 y $S 1$ en los versos 50, 59, 116, 296, 322, 462, 547, 561, 632, 668, 804, 985, 1024, 1093, 1197, 1219, 1325, 1404, 1478+,1515, 1717, 1603, 1616+, 1751, 1763, 2051, 127, 153, 270, 478, 668, 744, 752, 1254, 1739, 1832, 1906 y 1996. Asimismo, en la $\beta$ también encontramos variantes separativas en los versos 16, 18, 153, 222, 299, 302, 398, 578, 593, 617, 651, 817, $842,1756,2181,2339$ y 2465 . E1 y $S 1$ derivan de una la familia subarquetípica $\alpha$, proveniente del siglo XVII, mientras que $S 2$ y S3, de otra del siglo XVIII $(\beta)$. Entre las tradiciones subarquetípicas $(\alpha$ y $\beta)$ existen, sin duda, notables diferencias respecto al textus archetypus $(\chi)$, que, a su vez, daría lugar al texto ideal $(\omega)$. Proponemos, pues, el siguiente stemma codicum:

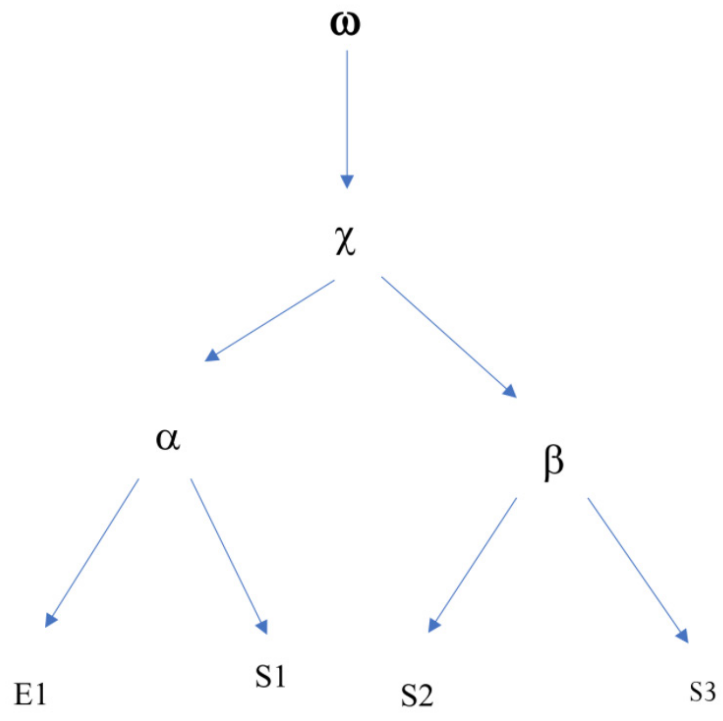




\section{La transmisión textual del manuscrito apógrafo M1}

En cuanto al dramatis personae, se producen varios cambios respecto a E1 (codex optimus) y a las ediciones sueltas (S1, S2, y S3). M1 parece seguir las ediciones de E1 y S1, ya que, frente a «En ella las personas siguientes» de $S 2$ y S3, incorpora «Personas» al inicio de la jornada. Por otra parte, sigue la lectura de «Cesarino, capitán de los sabinos» $(E 1, S 1)$, frente a la lectura incorrecta «Cesario, capitán de los sabinos», en donde la grafía $<$ n $>$ se omite. Sin embargo, M1 se olvida claramente de la preposición «de», naciendo así una nueva variante al preferir la elección adjetival («Cesarino, capitán sabino»), y no de complemento de núcleo-sustantivo:

0+ Personas E1 S1 M1 Hablan en ella las personas siguientes S2 S3

0+ Cesarino, capitán de los sabinos E1 S1 Cesario, capitán de los sabinos S2 Errata. Cesario, capitán de las sabinas S3 Errata Cesarino, capitán sabino M1.

M1 omite «Mujeres sabinas» en el dramatis personae, alejándose, por tanto, de E1, S1, S2 y S3. Por otra parte, trae la lectura correcta de «Tacio» (E1, S1) y no la incorrecta de $S 2$ y $S 3$ («Tácito»), que añaden por error $<t>$. Por otro lado, M1 aporta una variante nueva en el dramatis personae, ya que añade dos damas más a la obra - la dama primera y la segunda - y la referencia a la «Música», que, aunque no apareciera como tal en el dramatis personae, su presencia en E1, S1, S2 y S3 está atestiguada en dos momentos musicales (vv. 2108-2115; vv. 2190-2197):

0+ Mujeres sabinas E1 S1 S2 S3 Omitido en M1.

0+ Tacio E1 S1 M1 Tácito S2 S3 Errata.

0+ Dama primera M1 Omitido en E1 S1 S2 S3.

0+ Dama segunda M1 Omitido en E1 S1 S2 S3.

0+ Música M1 Omitido en E1 S1 S2 S3.

M1, al añadir dos damas más, crea a partir del verso 1630 un nuevo pasaje al final de la segunda jornada, en donde se produce el rapto de las sabinas. No obstante, parece ser que nunca se llegó a representar, puesto que en las páginas $20 \mathrm{v}, 20 \mathrm{r}$ y $21 \mathrm{v}$, de la segunda jornada aparecen cinco «NO» a los lados (imágenes $V$, VI y VII) y una raya a la izquierda para indicar que quizá no se tuvieran que llevar a escena: 
Salen Rómulo, Ostilio y romanos

Rómulo.

Todas las damas que encierra

Roma del sabino, ordeno

que al punto robadas sean

por blasón de los romanos

y por más venganza nuestra

que verá el tiempo en sus siglos

ni antiguas historias cuentan

a cada uno de los míos

permito que la sabina

que más rica le agrade

o porque a él se lo parezca

la llame ya «mía» y robe

al ruego o a la violencia. Vase.

OstiLIO. Ultraje Roma a Sabinia cuando ella su honor desprecia. Vase.

VOCES. ¡Venza el romano al sabino

vencido de sus bellezas!

Sale Ostilio luchando con una dama.

Ostilio. ¡Vamos, que en vano porfías...!

DAMA PRIMERA. ¡...en la traición!

Ostilio

¡...en fineza!

DAMA PRIMERA. ¡Ruin venganza!

OstiLio.

¡Amor

y en él no cabe! Llevala.

DAMA PRIMERA.

¡Violencia!

Sale por otro lado romano primero y otra dama segunda.

ROMANO PRIMERO. ¡Sígueme!

DAMA SEGUNDA. ¡Mis tiernos años

y estas lágrimas te muevan!

Romano Primero. ¡Oí[d]! Pues tenemos licencia 
para robar de esta concha,

Tú sola has de ser la perla,

que eres la niña bonita,

Aunque el sabino en tu ausencia

Diga que se la llevaron

y que a él el alma le llevan.

Dama SEGUNDA. ¿Y qué dirán?

ROMANO PRIMERO. ¡Lo que quieran! Llevala.

Sale Ostilio [por un] lado, Romano segundo y otra dama tercera.

Romano segundo. ¡Ven conmigo, pues que ves

que ya nadie hay que os defienda!

DAMA TERCERA. ¡Los dioses tomen venganza

de tiranías tan nuevas!

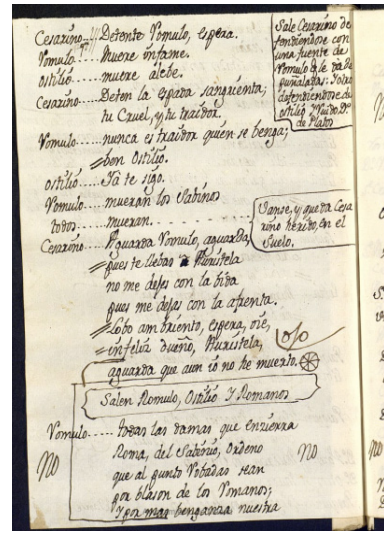

Imagen VII. Versos añadidos y tachados en los márgenes (fol. 2r, II jornada).

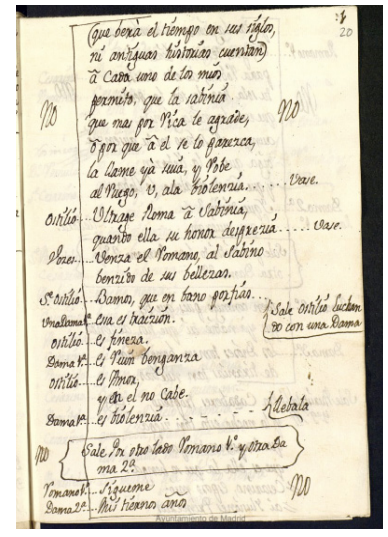

Imagen VIII. Versos añadidos y tachados en los márgenes (fol. 1v, II jornada).

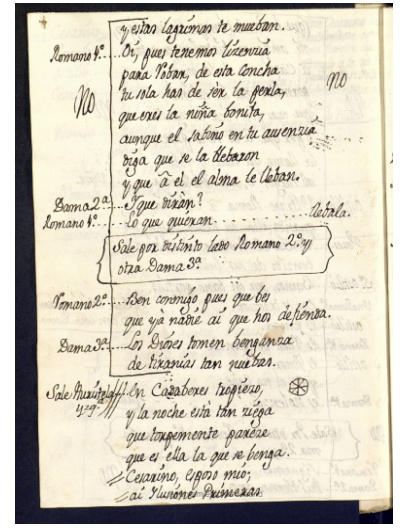

Imagen IX. Versos añadidos y tachados en los márgenes (fol. $1 r$, II jornada).

Las acotaciones de E1, S1, S2 y S3 cambian notablemente en M1 y pueden darnos pistas sobre cómo se interpretó la comedia a finales del siglo XVIII. En este punto, son, por un lado, variantes separativi de las ediciones sueltas - S1, S2 y S3 - y la publicada en las Comedias escogidas... de Gregorio Rodríguez. Asimismo, son variantes adiafóricas, ya que no cambian sustancialmente el texto, pues las acotaciones forman 
parte del paratexto. Aunque las hemos añadido en el aparato de variantes que incorporamos al final del artículo, consideramos oportuno compararlas en conjunto:

VERSO

$3+$

$226+$

$306+$

$371+$

$463+$

$516+$

$727+$

$751+$

$899+$

$957+$

$1478+$

$1599+$

\section{Acotación en E1 S1 S2 S3}

Sale Rómulo vestido de pieles con las manos ensangrentadas deteniendo a Ostilio, y a Flabio y Ascanio, con las espadas desnudas, y todos vestidos de pieles.

Salen Aurelio soldado con Pasquín y Libia, graciosos, y traélos atados.

Tocan un clarín.

Dentro Auristela dice un verso y sale con soldados y las espadas desnudas.

\section{Acotación en M1}

Sale Rómulo vestido de pieles con las manos ensangrentadas deteniendo a Ostilio, y a Flabio y Ascanio, con las espadas desnudas.

Sale Aurelio, soldados con Pasquín y Libia, graciosos que los trae atados.

Tocan clarín.

Dentro Auristela y sale con los sabinos con espadas desnudas.

Pónese por la puerta que se fue Au- Vase con todos. ristela defendiendo el paso.

Tocan cajas y clarines y sale Cesari- Vanse, tocan caja y clarín y sale no muy galán con bengala y Rosmi- Cesarino con gala con bastón y ra, segunda dama.

Rosmira.

Tocan cajas y clarines y sale Auristela y damas y Cesarino sale a recibirla.

Tocan clarín dentro.

Vanse todos los sabinos.

Sale Cesarino y Rosmira ya acompañados.

Vanse, tocan cajas y clarines y sale Rómulo por una puerta y, por otra, soldados y Ostilio con bandas negras. pañados.

Vanse y quedan Libia y Pasquín. Tocan chirimías, bailan y cantan y a otro lado ruido.
Vanse todos los graciosos, tocan instrumentos y cantan y bailan dentro, y a otro lado suena ruido y pasan algunos criados con platos cubiertos. 
Sale Cesarino herido, dándole de puñaladas Rómulo, y él ensangrentado defendiéndose con una fuente en la mano, y otro defendiéndose de Ostilio, y rueden platos y empanadas.

$1661+$

1661+ Tocan cajas y clarines y sale Cesarino.

1769+ Tocan dentro y dicen.

2092+ Vanse y tocan chirimías y cajas y salen los músicos y Rómulo, Ostilio, Fabio, Ascanio y Aurelio, Libia y Auristela, y todas las mujeres de gala.

2356+ Estando en la fuga del sarao tocan clarines y cajas y dice Rómulo.

2358+ Dentro Cesarino.

2383+ Sale Cesarino.
Sale Cesarino deteniéndose con una fuente de Rómulo dándole de puñaladas y otro defendiéndose de Ostilio y ruidos de platos.

Fin de la segunda jornada.

Caja y clarines y sale Cesarino.

Clarín y voz.

Vanse, tocan chirimías y salen los músicos de dos en dos y galanes en trajes diferentes y Rómulo y con la música forman un sarao.

Tocan cajas y clarines.

Vanse todos y dentro Cesarino.

La acotación 3+ de E1, S1, S2 y S3 indicaba claramente la rusticitas de los personajes romanos al igual que en las fuentes clásicas. No obstante, es probable que no fuese así en la representación dieciochesca, al eliminar «todos vestidos de pieles», y que los romanos estuviesen vestidos de una forma más elegante que en la representación áurea. La acotación 516+ de M1 no deja de ser llamativa, ya que Cesarino porta «un bastón». ¿Quiere decir, pues, que en el siglo XVIII se convirtió en un personaje de mayor edad y dejó la veintena o la treintena o, por el contrario, el bastón es símbolo de poder y dominación?

Aunque no nos han llegado grandes datos sobre la representación dieciochesca de esta comedia en colaboración, existe en la Biblioteca Histórica de Madrid una partitura también del siglo XVIII con signatura Mus. 16-20 que indica que, efectivamente, El robo de las sabinas se representó en algún momento con música. Así, se trata de un texto con música polifónica, escrita en clave de sol y de fa, para dos violines, dos oboes, dos trompas, contrabajo y clave, además de voces. Sin embargo, no podemos afirmar con total seguridad si la partitura fue compuesta en el siglo XVII o bien en el XVIII por los pocos datos que tenemos sobre ella. 
Sin embargo, en $M 1$ tenemos, pues, constancia de la importancia de las voces, de los clarines y de los tambores durante las representaciones en ambos siglos, como indican 306+, 516+, 727+, 751+, 1478+, 1599+, 1661+, 1769+, 2092+ y 2356+. Así pues, 2092+ y 2356+ reflejan, tanto en E1, S1, S2 y S3, como en M1, que los personajes bailaban un «sarao» durante la representación.

Una vez analizadas las acotaciones y los versos añadidos a partir de 1629, conviene estudiar los cambios y supresiones. Al comienzo justamente de la tercera jornada, en el verso 1665, M1 incorpora los siguientes versos:

\section{Voces dentro.}

VOCES. ¡Haced alto en el monte convecino y solo a Tacio y a Cesarino!

Cabe destacar que este manuscrito apógrafo contiene varias tachaduras a lo largo de las tres jornadas. En el verso 29 («Y decid, ¿cuáles son?»), se añade la conjunción «pues» en la página $23 \mathrm{v}$ de la primera jornada de M1 («Y decid, pues, ¿cuáles son?»), causando, por tanto, un verso hipermétrico en la tirada de silvas pareadas que no aparece en E1, S1, S2 ni S3, por tanto, se trata de una variante separativi. En el verso 51, aparece una tachadura ilegible en $23 \mathrm{r}$ y justamente arriba aparece la lectura correcta que traen las ediciones E1, S1, S2 y S3: «me mostré».

En nuestra edición crítica, hemos elegido la variante conjuntiva de $S 2$ y $S 3$ («impía») en el verso 66, ya que consideramos mediante emendatio ope ingenii que la de $E 1$ y $S 1$ («misma») no encaja en la tirana de silvas pareadas, ya que no rima en consonante con el resto de versos. En este sentido, M1 trae la tachadura de la variante conjuntiva de E1 y S1 («por ella misma»), añadiendo una nueva lectio: «saña impía», que es, a su vez, una variante separativa de la familia de E1-S1 y S2-S3.

66 que os es impía S2 S3 que ella misma E1 S1 saña impía M1

En el verso 224 («desconocidos e ingratos»), se corrige la conjunción «y» (variante de $E 1, S 1$ y S3) por «e», variante única de S2, por lo que se podría tratar de un caso de contaminatio textual: por una parte, escoge la variante de la familia a, que también aparece en $S 3$, y, posteriormente, la de $S 2$ :

224 desconocidos y ingratos E1 S1 S3 desconocidos e ingratos S2 M1 


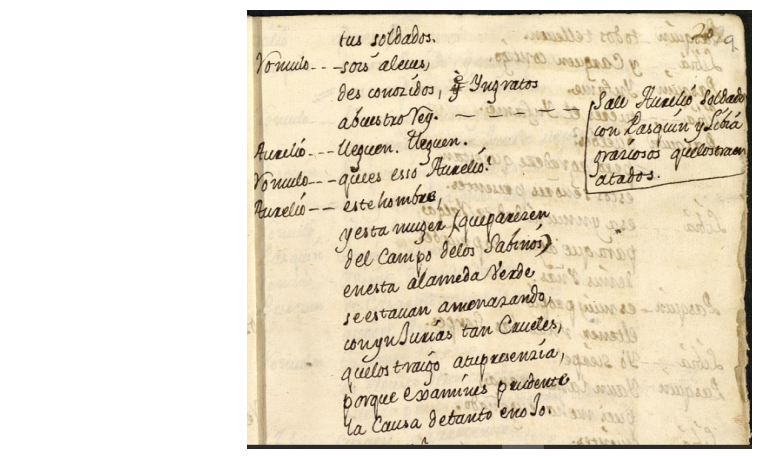

Imagen X. Ejemplo de contaminatio del manuscrito M1, en donde el copista tacha «y» por «e» (v. 224).

Otro caso de contaminatio se produce en el verso 403, en donde E1 y S1 traen la lectura «espero», frente a $S 2$ y $S 3$ («esposo»). A pesar de que E1 es el codex optimus, la variante de este verso está deturpada respecto al codex archetypus, ya que mediante la emendatio ope ingenii, consideramos que el sustantivo «esposo» se refiere a Cesarino. En este punto, M1 tacha la variante de la familia $\alpha$, escogiendo la conjuntiva de $\beta$ :

403 en mi esposo S2 S3 M1 en mi espero E1 S1

En el verso 404 sucede lo mismo: existe una tachadura de «flechas hay» (lectura de E1 y S1) y una corrección por «flechas soy» (lectura de S2 y S3), al igual que en el 414, donde se tacha la variante hipermétrica de E1 y $S 1$ («furiosas») y se escoge la de $S 2$ y $S 3$, que es la que también hemos seleccionado en nuestra edición crítica.

404 flechas hay E1 S1 fechas soy S2 S3 M1

414 furias S2 S3 M1 furiosas E1 S1 Hipermetría. 


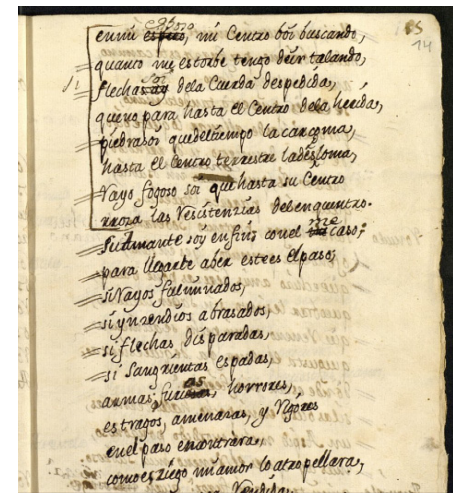

Imagen XI. Ejemplo de contaminatio del manuscrito M1, en donde el copista tacha «espero» por «esposo» (v. 403).

En cuanto a las adiciones y supresiones, en el folio $15 \mathrm{v}$ de la primera jornada, se corrigen los versos 408 y 409 («rayo fogoso soy, en fin, con él me caso, / para llegarle a ver este es el paso») por «rayo fogoso soy que hasta su centro/ roza las resistencias del encuentro/justamente soy en fin con él me caso», también con rima consonante al ser silvas pareadas. En el folio 12v, se corrige en el verso 508 el sintagma nominal «la gloria» por «el gusto», distanciándose, pues, de todas las variantes de E1, S1, S2 y S3; en el verso 514, se añade el sustantivo «afecto», formando un verso hipermétrico que dista también del resto de ediciones, de la misma forma que en el 523 se corrige «partes» por «prendas»; en el verso 590, «divino» por «diurno»; en el 622, el artículo «la», creando, de nuevo, una hipermetría; en el 679, «medró» por «me dio»; en el 759, «admito» por «admitimos»; en el 777, la conjunción «pues» por «mas»; en el 799, «mi poder es infinito» por «mi poder constante y fijo»; en el 883, «enmendarte» por «enseñarte»; en el 995, «y ella con la voz me agasajaba» por «si bien aún con la voz me agasajaba»; en el 1385, «ha turbado» por «ha postrado» y en 1359 los siguientes, que tampoco aparecen en $E 1, S 1, S 2$ y $S 3$ :

Cesarino. $\quad[\ldots]$ Dile a Rómulo que todos

Admitimos sus obsequios

y que partiremos promptos

A lograr de sus festejos.

OstiLIO. Harás feliz con tu visita

a Roma. ¡Guárdate el cielo! Vase. 
Así, se produce una amplificatio en la segunda jornada en el diálogo que mantiene Ostilio, que actúa como embajador de Rómulo, con Cesarino, capitán de los sabinos. Además, en el verso 1370 se cambia «divina» por «brillante». Asimismo, las acotaciones de los versos 1493 y 1498 de E1, S1, S2 y S3 indicaban $\left\langle 1^{\circ} »,\left\langle 2^{\circ} », \ll 3^{\circ} » y \ll 4^{\circ} »\right.\right.$. En nuestra edición crítica corregimos entre corchetes e indicamos «Soldado $1^{\circ}$ », «Soldado $2^{\circ}$ », «Soldado $3^{\circ}$ » y «Soldado $4^{\circ} »$, puesto que nos basamos en el verso 1486 («iNo somos tus soldados!»):

[SOLDADO] $1^{\circ}$.

[SOLDADO $2^{\circ}$.

[SOLDADO] $3^{\circ}$.

[SOLDADO] $4^{\circ}$.

ToDos.
No es sino porque, habiéndola negado

el sabino, no solo no has tomado

la venganza que debes, pero hoy haces

contra nuestro valor injustas paces y en señal de esta paz hoy les prometes...

...músicas....

...juegos...

...luchas...

...y banquetes.

Sin embargo, el copista de M1 también alteró las acotaciones y, en lugar, de escoger el sustantivo «soldado» como nosotros prefirió añadir «romano», que sigue siendo igual de válido:

[ROMANO] $1^{\mathrm{o}}$.

[ROMANO] $2^{\circ}$.

[ROMANO] $3^{\circ}$.

[ROMANO] $4^{\mathrm{O}}$.

ToDos.
No es sino porque, habiéndola negado

el sabino, no solo no has tomado

la venganza que debes, pero hoy haces

contra nuestro valor injustas paces

y en señal de esta paz hoy les prometes...

...músicas....

...juegos...

...luchas...

...y banquetes.

En el verso 1751, M1 trae la variante tachada de E1, S1, S2 y S3 («matar con bizarría donde hay agravio») y la cambia: «matar con bizarría en el agravio»; en el verso 2097, «bajel» por «babel»; en el 2249 se modifica «Eso se lo han levantado» por «Eso solo se ha contado»; en el 2429, «perplejas» por «sus- 
pensas»; y en el 2505, «mano» por «esposa», siendo todas ellas, por tanto, variantes separativi.

\section{Conclusiones}

Teniendo en cuenta las peculiaridades textuales de $M 1$, proponemos el siguiente stemma codicum:

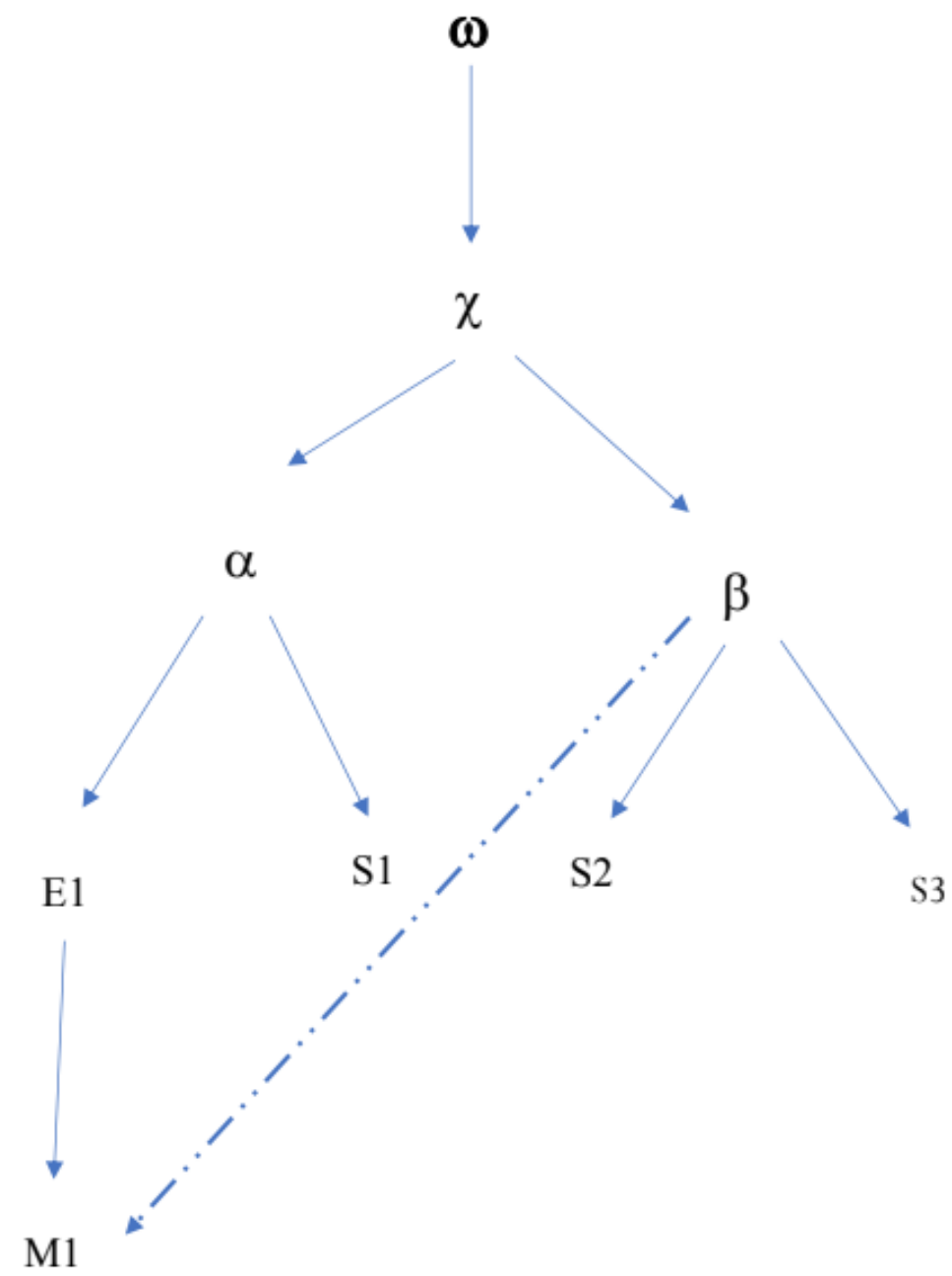


La edición de M1 procede directamente de E1, puesto que encontramos diversas variantes coniunctivi entre ambas en los versos 3,16, 17, 18, 51, 112, 116, 222, 243, 270, 275, 183, 296, 302, 322, 330, 338, 398, 248, 428, 462, 478, 480, $547,561,578,588,593,617,632,633,639,651,668,675,726,738,744,752,760$, $800,804,833,842,891,900+, 934,950,974,985,1024,1051,1055,1077,1093$, $1125,1197,1219,1254,1262,1268,1288,1325,1352,1424,1603,1607,1625$, $1702,1717,1739,1740,1746,1750,1755,1762,1763,1767,1827,1831,1880$, 1905, 1929, 1954, 1998, 2002, 2051, 2133 2135, 2169, 2187 2214, 2243, 2250, $2151,2254,2328,2370,2440,2465,2475,2495,2507$ y 2515. En 804 existe una variante separativa respecto a $E 1$, ya que subsana el error agramatical del verbo pasivo perifrástico y también la reduplicación de la $<\mathrm{t}>$ en 2145 por emendatio ope ingenii.

Por otra parte, M1 y E1 presentan variantes separativi en tanto que se ha detectado una contaminatio con el texto archetypus de la familia $\beta$, puesto que el copista de este manuscrito apógafo optó por seguir el texto subarquetípico en los versos 118, 291, 308, 362, 366, 403, 432, 456, 1001, 2360 y 2486, en los que se rechaza la lectura de E1. En este sentido, la contaminatio se percibe gráficamente debido a las numerosas tachaduras en la edición M1. Desechamos, por tanto, la posibilidad de que descienda de $S 1$ por las variantes separativi entre ambas, concretamente en los versos 50, 59, 116, 296, 322, 462, 547, 561, 632, 668, 804, 985, 1024, 1093, 1197, 1219, 1325, 1404, 1478+,1515, 1717, 1603, $1616+, 1751,1763,2051,127,153,270,478,668,744,752,1254,1739,1832,1906$ y 1996.

El manuscrito está plagado de tachaduras en diversas páginas en las que justo encima se incorpora la palabra correcta, ya que el copista sería bien una persona insegura, bien escribiría rápido con ciertos fallos que tendría que enmendar. Además, también cambia ciertos fragmentos e incorpora nuevos, como, por ejemplo, los ejemplos anteriores a partir del verso 1630, por lo que el dramatis personae de $M 1$ se altera ligeramente al incorporar dos nuevas damas. No creemos, pues, que estos versos se llegaran a representar por las tachaduras que presentan en los márgenes (imágenes V, VI y VII). Sin duda, los cambios más destacables se producen en las acotaciones, que, aunque no alteran en el texto dramático en sí, aportan pistas sobre cómo pudo ser la representación de El robo de las sabinas. De esta forma, hemos analizado que la música siguió jugando un papel importante en la obra, junto con los bailes, 
especialmente el sarao $(2092+$ y $2356+)$. Por otra parte, parece posible que el vestuario rústico de los sabinos que vestían en el siglo XVII se refinase $(3+)$ y que Cesarino dejase de ser un joven para pasar a ser un adulto de mayor edad, al portar un bastón (516+).

\section{Bibliografía}

Alviti, Roberta y Almudena García GonZÁlez (2015), «Obras en colaboración», en Rafael González Cañal (coord.), El universo dramático de Rojas Zorrilla, Valladolid, Universidad de Valladolid, págs. 91-105.

Barrera y Leirado, Cayetano Alberto de la (1860), Catálogo bibliográfico y biográfico del teatro antiguo español: desde sus orígenes hasta mediados del siglo XVIII, Madrid, Imprenta y Estereotipia de M. Rivedeneyra.

Blecua Perdices, Luis Alberto (1983), Manual de crítica textual, Madrid, Castalia.

FAJARDO, Juan Isidro (1717), Título de todas las comedias que, en verso español y portugués, se han impreso hasta el año de 1716, Madrid.

García de la Huerta, Vicente (1785), Theatro español, catálogo alphabético de las comedias, tragedias, autos, zarzuelas, entremeses y otras obras..., Madrid, Imprenta Real.

GonZÁlez CAÑAL, Rafael (2017), «La colaboración de Rojas con los hermanos Coello: El robo de las sabinas», en Juan Matas Caballero (ed.), La comedia escrita en colaboración en el teatro del Siglo de Oro, Olmedo, Ayuntamiento de Olmedo/ Universidad de Valladolid, págs. 113-123.

- (2015), «Corpus, autorías y atribuciones», en Rafael González Cañal, (coord.), El universo dramático de Rojas Zorrilla, Valladolid, Universidad de Valladolid, págs. 25-36.

- ; Cerezo Rubio, Ubaldo y Germán Vega García-Luengos (2007), Bibliografía de Francisco de Rojas Zorrilla, Kassel, Reichenberger.

Medel del Castillo, Francisco (1735), Índice general alfabético de todos los títulos de comedias que se han escrito, Madrid, Imprenta de Alfonso de Mora. 
Pérez Priego, Miguel Ángel (2010), La edición de textos, Madrid, Síntesis.

Rojas Zorrilla, Francisco de (2021), Obras completas. Volumen IX. Comedias sueltas, eds. Rafael González Cañal y Almudena García González, Cuenca, Universidad de Castilla-La Mancha.

- (2018), Obras completas. Volumen VII. Tragedias sueltas, eds. Felipe B. Pedraza Jiménez, Rafael González Cañal y Milagros Rodríguez Cáceres, Cuenca, Universidad de Castilla-La Mancha.

- (2017), Obras completas. Volumen VI. Segunda parte de comedias de Francisco de Rojas Zorrilla, eds. Felipe B. Pedraza Jiménez, Rafael González Cañal y Milagros Rodríguez Cáceres, Cuenca, Universidad de Castilla-La Mancha.

- (2014), Obras completas. Volumen V. Segunda parte de comedias de Francisco de Rojas Zorrilla, eds. Felipe B. Pedraza Jiménez, Rafael González Cañal y Elena E. Marcello, Cuenca, Universidad de Castilla-La Mancha.

- (2011a), Obras completas. Volumen IV. Segunda parte de comedias de Francisco de Rojas Zorrilla, eds. Felipe B. Pedraza Jiménez, Rafael González Cañal y Milagros Rodríguez Cáceres, Cuenca, Universidad de Castilla-La Mancha.

- (2011b), Obras completas. Volumen III. Primera parte de comedias de Francisco de Rojas Zorrilla, eds. Felipe B. Pedraza Jiménez, Rafael González Cañal y Gemma Gómez Rubio, Cuenca, Universidad de Castilla-La Mancha.

- (2009), Obras completas. Volumen II. Primera parte de comedias de Francisco de Rojas Zorrilla, eds. Felipe B. Pedraza Jiménez, Rafael González Cañal y Juan José Pastor Comín, Cuenca, Universidad de Castilla-La Mancha.

- (2007), Obras completas. Volumen I. Primera parte de comedias de Francisco de Rojas Zorrilla, eds. Felipe B. Pedraza Jiménez, Rafael González Cañal y Elena E. Marcello, Cuenca, Universidad de Castilla-La Mancha. 
Aparato de variantes

\section{Siglas UTILIZADAS EN EL APARATO DE VARIANTES}

E1 En Parte 11 de comedias nuevas escogidas..., Madrid, Gregorio Rodríguez, a costa de Juan S. Vicente, 1685.

S1 El robo de las sabinas, s.l., s.i., s.a.

S2 El robo de las sabinas, Sevilla, Manuel Nicolás Vázquez, s.a.

S3 El robo de las sabinas, Madrid, Antonio Sanz, 1754.

M1 El robo de las sabinas, Madrid, ms. Tea 1-60-13, A.

\section{ARIANTES}

Tírulo El robo de las Sabinas. / Por don Juan Coello y Arias E1 S1 S3 El robo de las Sabinas. / Por don Juan Coello y Arias. Lleua En el fin el entremés de Las burlas del Doctor Juan Rana S2 Comedia famosa / El robo de las sabinas/ su autor / don Juan Coello y Arias M1

0+ $\quad$ Personas E1 S1 M1 Hablan en ella las personas siguientes S2 S3

0+ $\quad$ Cesarino, capitán de los Sabinos E1 S1 Cesario, capitán de los Sabinos S2 Error Cesario, capitán de las Sabinas S3 Errata Cesarino, capitán sabino $M 1$.

0+ $\quad$ Mujeres sabinas E1 S1 S2 S3 Omitido en M1.

0+ $\quad$ Tacio E1 S1 M1 Tácito S2 S3 Errata.

0+ $\quad$ Soldados sabinos E1 S1 M1 Omitido en S2 S3.

0+ $\quad$ Dama primera M1 Omitido en E1 S1 S2 S3.

0+ $\quad$ Dama segunda M1 Omitido en E1 S1 S2 S3.

0+ $\quad$ Música M1 Omitido en E1 S1 S2 S3.

0+ $\quad$ Jornada primera S2 S3 M1 Omitido en E1 S1.

0+ $\quad$ Después de haber tocado cajas y clarines, dicen dentro E1 S1 S2 S3 Casa Clarín y voces dentro M1.

3 matalde E1 S1 M1 matadle S2 S3. 
3+ Sale Rómulo vestido de pieles con las manos ensangrentadas deteniendo a Ostilio, y a Flabio y Ascanio, con las espadas desnudas, y todos vestidos de pieles E1 S1 S2 S3 Sale Rómulo vestido de pieles con las manos ensangrentadas deteniendo a Ostilio, y a Flabio y Ascanio, con las espadas desnudas M1 la vida E1 S1 S3 M1 la vido S2 Errata. sellad E1 S2 S3 M1 selad S1 Errata. mi agravio E1 S1 S3 M1 mi agravia S2 Errata. Y decid, ¿cuáles son? E1 S1 S2 S3 Y decid, pues, ¿cuáles son? M1.

41 en efeto E1 S1 S2 en efecto S3 M1. justiciero E1 S2 S3 M1 justicero S1 Errata. mis leyes E1 S2 S3 M1 leys S1 Errata. que os es impía S2 S3 que ella misma E1 S1 saña impía M1. substituye E1 S1 S3 sobstituye S2 M1. propiedad E1 S1 S3 M1 propriedad S2.

116 emprende E1 S2 S3 M1 emprendes S1 Errata.

118 vitorias E1 S1 victorias S2 S3 M1.

127 escuchar E1 S2 S3 M1 esuchar S1 Errata.

153 amortigua E1 S3 M1 amortiga S1 Errata. amorrigua S2 Errata.

222 sois E1 S1 S3 seis S2 Errata.

223 desconocidos y ingratos E1 S1 S3 desconocidos e ingratos S2 M1.

225+ Salen Aurelio soldado con Pasquín y Libia, graciosos, y traélos atados E1 S1 S2 S3 Sale Aurelio, soldados con Pasquín y Libia, graciosos que los trae atados $M 1$.

235 Bercebú E1 S2 S3 Bersebú S1 M1.

243 propio E1 S3 M1 proprio S1 S2.

265 arrepentiros E1 S2 S3 M1 arremptentiros S1 Errata.

$270 \quad$ caseme E1 S2 S3 M1 casarme S1.

275 la consumida yo soy E1 S1 M1 la consumida soy yo S2 S3.

283 impropia E1 S3 M1 impropria S1 S2.

291 defendeldas, apoyaldas E1 S1 defendedlas, apoyadlas S2 S3 M1. 
296 rencillas E1 S2 S3 M1 rencilhas S1 Errata.

299 señor yo E1 S1 S3 señor S2 Hipometría.

302 mosquete E1 S1 S3 mosquere S2 Errata.

305+ Tocan un clarín E1 S1 S2 S3 Tocan clarín M1.

308 porque le hieren S2 S3 M1 porque leyeren E1 S1.

$309 \quad$ al aire E1 S1 S3 M1 a el aire S2.

322 valiente E1 S2 S3 M1 valliente S1 Errata.

330 exercito E1 S2 S3 M1 execito S1 Errata.

338 ansí E1 S1 M1 assí S2 S3.

362 vuelven E1 S1 vuelve S2 S3 M1 Errata.

364 soeces S2 S3 M1 sueces E1 S1.

366 los efetos E1 S1 los efectos S2 S3 M1.

$371+\quad$ Dentro Auristela dice un verso y sale con soldados y las espadas desnudas E1 S1 S2 S3 Dentro Auristela y sale con los sabinos con espadas desnudas M1.

374+ $\quad$ Sale Auristela E1 S1 S2 S3 Salen ahora todos M1.

398 diciendo E1 S1 S3 M1 diciende S2 Errata.

$403 \quad$ en mi esposo S2 S3 M1 en mi espero E1 S1.

405 flechas hay E1 S1 fecha soy S2 S3 M1.

408 rayo fogoso soy, en fin, con él me caso E1 S1 S2 S3 rayo fogoso soy que hasta su centro M1.

409 para llegarle a ver este es el paso E1 S1 S2 S3 roza las resistencias del encuentro M1.

409 justamente soy en fin, con él me caso Añadido en M1 Omitido en E1 S1 S2 S3.

415 furias S2 S3 M1 furiosas E1 S1 Hipermetría.

428 parezca E1 S2 S3 M1 paresca S1.

432 obrar S2 S3 M1 obra E1 S1.

456 tus deidades E1 S1 tu deidad S2 S3 M1.

462 me allanad E1 S2 S3 M1 allanad S1.

463+ Pónese por la puerta que se fue Auristela defendiendo el paso E1 S1 S2 S3 Vase con todos M1.

$478 \quad$ propia E1 S1 S3 M1 propria S2. 
tan afable E1 S2 S3 M1 más afable S1.

509 la gloria E1 S1 S2 S3 el gusto M1.

515 afecto M1 Verso hipermétrico. Omitido en E1 S1 S2 S3.

516+ Tocan cajas y clarines y sale Cesarino muy galán con bengala y Rosmira, segunda dama E1 S1 S2 S3 Vanse, tocan caja y clarín y sale Cesarino con gala con bastón y Rosmira M1.

524 partes E1 S1 S2 S3 prendas M1.

$547 \quad$ puedo E1 S2 S3 M1 pudo S1 Errata.

561 disculpa E1 S2 S3 M1 desculpa S1.

564 satisfación E1 S2 S3 M1 satisfacción S3.

578 para nacer E1 S1 S3 M1 pata nacer S2 Errata.

$588 \quad$ noturno E1 S1 M1 nocturno S2 S3.

$590 \quad$ divino E1 S1 S2 S3 diurno M1.

$593 \quad$ huella E1 S1 S3 M1 hoella S2 Errata.

617 comunica E1 S1 S3 M1 comanica S2 Errata.

622 luz E1 S2 S1 S3 la luz M1.

632 retrocediendo E1 S2 S3 M1 retrocidiendo S1.

633 permitir E1 S2 S3 M1 premitir S1 Errata.

639 en él E1 S1 S3 M1 con él S2.

651 estoy loco E1 S1 S3 M1 estos loco S2 Errata.

668 es ofenderme E1 S2 S3 M1 es de ofenderme S1 Hipermetría.

675 con ligereza E1 S2 S3 M1 con liguereza S1 Errata.

$700 \quad$ medró E1 S1 S2 S3 me dio M1.

700 descubriole E1 S2 S3 M1 descrubiole S1 Errata.

726 fin mis esperanzas tienen E1 S1 M1 en mis esperanzas tienen S2 S3.

728+ Tocan clarines y cajas, y sale Auristela, acompañada de todas las damas, y sale Cesarino a recibirla E1 S1 S2 S3 Tocan cajas y clarines y sale Auristela y damas y Cesarino sale a recibirla M1.

738 decildo E1 S1 decidlo S2 S3.

744 he tenido E1 S2 S3 M1 ha tenido S1 Errata.

751 propios E1 M1 proprios S1 S2 S3. 
752+ Tocan un clarín E1 S1 S2 S3 Tocan clarín dentro M1.

752 el alma E1 S2 S3 M1 el asma S1 Errata.

$760 \quad$ admito E1 S1 S2 S3 admitimos M1.

762 presencia E1 S2 S3 M1 precencia S1 Errata.

778 Pues ¡qué importa! ¡Qué delirios! E1 S2 S3 Pues ¡qué importa! ¡Qué dilirios S1 Mas, ¡qué importa! ¡Qué delirios! M1.

800 mi poder es infinito E1 S1 S2 S3 mi poder constante y fijo M1.

804 son temidos S1 S2 S3 M1 son temido E1 Errata.

817 soberbia E1 S1 S3 M1 sobevia S2 Errata.

833 agasajo E1 S1 S3 M1 agasaio S1 Errata.

$842 \quad$ siendo E1 S1 S2 M1 sieudo S3 Errata.

883 enmendarte E1 S1 S2 S3 enseñarte M1.

891 mis acciones E1 S2 S3 M1 mis accionea S1 Errata.

900+ Vanse todos E1 S1 Vanse todos los sabinos S2 S3.

$934 \quad$ propias E1 S1 S3 M1 proprias S2.

$950 \quad$ adoctivo E1 $S 1 M 1$ adoptivo S2 S3.

957+ $\quad$ Sale Cesarino y Rosmira E1 S1 S2 S3 Sale Cesarino y Rosmira ya acompañados $M 1$.

974 le fié E1 S1 M1 la fié S2 S3.

985 enemiga E1 S2 S3 M1 inimiga S1.

995 y ella con la voz me agasajaba E1 S1 S2 S3 si bien aún con la voz me agasajaba $M 1$.

$1001 \quad$ a voces S2 S3 M1 a veces E1 S1.

1024 despiertan E1 S2 S3 M1 dispiertan S1.

1047 me dad consejo S1 M1 dad consejo E1 S2 S3 Hipometría.

1051 creída E1 S1 S3 M1 crecida S2.

1055 gallarda E1 S2 S3 M1 guallarda S1 Errata.

1077 desbocado viento E1 S1 S3 M1 desbocado el viento S2.

1093 Himeneo E1 S2 S3 M1 Himeo S1 Hipometría.

1125 propio E1 S1 S3 M1 proprio S2.

1197 le querrás E1 S2 S3 M1 le quererás S1 Hipermetría.

1219 importan E1 S2 S3 M1 importa S1 Errata. 
1254 preceptos E1 S2 S3 M1 proceptos S1 Errata.

1262 sostituyan E1 S1 M1 sobstituyan S2 S3.

1268 ya arrestado u desatento S2 S3 de arrestado, desatento E1 S1 M1.

1288 leyes E1 S2 S3 M1 leys S1 Errata.

1325 Baco E1 S2 S3 M1 Bacco S1.

1350 prueben E1 S1 S3 prueban S2 Errata.

1352 les desate E1 S1 S3 M1 se desate S2.

1360

Versos

añadidos

en $M 1$

Omitidos

en E1 S1

S2 S3

1370 divina E1 S1 S2 S3 brillante M1.

1385 ha turbado E1 S1 S2 S3 ha postrado M1.

1404 acuerdo E1 S2 S3 M1 acurrdo S1 Errata.

1406 inumerable E1 M1 innumerable S2 S3 inumerabel S1 Errata.

1424 agora E1 S1 M1 ahora S2 S3.

1478+ Tocan clarines y tambores y salgan Rómulo por una puerta y, por otra, soldados con bandas negras y Ostilio con ellos con banda S1 S2 S3 Tocan clarines y tambores y salgan Rómulo por una puerta y, por otra, soldados con bandas negras y Ostilio con ellos con banda E1 Errata Vanse, tocan cajas y clarines y sale Rómulo por una puerta y, por otra, soldados y Ostilio con bandas negras M1.

1515 y voz E1 S2 S3 M1 y la voz S1 Hipermetría.

1567+ Entran Cesarino, Auristela, Rosmira, Libia y damas y Pasquín muy adornados todos E1 S1 S3 Entra Cesarino, Auristela, Rosmira, Libia y damas y Pasquín muy adornados todos $S 2$ Errata Salen Cesarino, Auristela, Rosmira, Libia y damas Pasquín todos de gala M1. 
1571+ Abrazando a cada una E1 S1 S2 S3 Abrazalas a todas M1.

1599+ Vanse y quedan Libia y Pasquín. Tocan chirimías, bailan y cantan y a otro lado ruido E1 S1 Vanse y quedan Libia y Pasquín. Toca chirimías, bailan y cantan y a otro lado ruido S2 S3 Vanse todos los graciosos, tocan instrumentos y cantan y bailan dentro, y a otro lado suena ruido y pasan algunos criados con platos cubiertos $M 1$.

1603 Pipiripao E1 S2 S3 M1 Piripao S1 Errata.

1604+ $\quad$ viandas S2 S3 M1 vandas E1 S1 Errata.

1607 envidan E1 S1 M1 envian S2 S3.

1616+ Sale Cesarino herido, dándole de puñaladas Rómulo, y él ensangrentado defendiéndose con una fuente en la mano, y otro defendiéndose de Ostilio, y rueden platos y empanadas E1 S2 S3 Sale Cesarino herido, dando de puñaladas Rómulo, y él ensangrentado defendiéndose con una fuente en la mano, y otro defendiéndose de Ostilio, y rueden platos y empanadas S1 Sale Cesarino deteniéndose con una fuente de Rómulo dándole de puñaladas y otro defendiéndose de Ostilio y ruidos de platos M1.

1625 te llevas a Auristela S2 S3 te llevas Auristela E1 M1 te lleva Auristela S1.

1629 Versos añadidos en M1 Omitidos en E1 S1 S2 S3

Salen Rómulo, Ostilio y romanos

Rómulo. Todas las damas que encierra

Roma del sabino, ordeno

que al punto robadas sean

por blasón de los romanos

y por más venganza nuestra

que verá el tiempo en sus siglos

ni antiguas historias cuentan

a cada uno de los míos

permito que la sabina

que más rica le agrade 


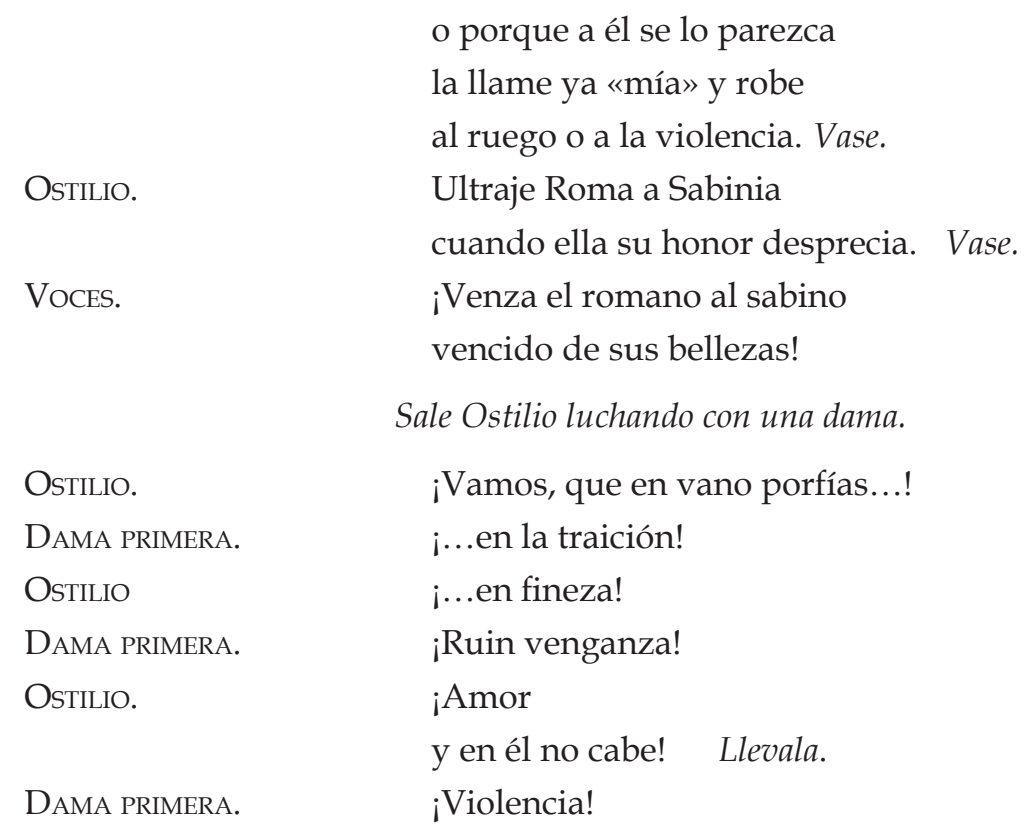

Sale por otro lado romano primero y otra dama segunda.

ROMANO PRIMERO. ¡Sígueme!

DAMA SEgUnda. ¡Mis tiernos años

y estas lágrimas te muevan!

ROMANO PRIMERO. ¡Oí[d]! Pues tenemos licencia

para robar de esta concha,

Tú sola has de ser la perla,

que eres la niña bonita,

Aunque el sabino en tu ausencia

Diga que se la llevaron

y que a él el alma le llevan.

DAMA SEGUNDA. ¿Y qué dirán?

ROMANO PRIMERO. ¡Lo que quieran! Llevala.

Sale Ostilio [por un] lado, Romano segundo y otra dama tercera.

ROMANO SEGUNDO. ¡Ven conmigo, pues que ves

que ya nadie hay que os defienda!

DAMA TERCERA. ¡Los dioses tomen venganza

de tiranías tan nuevas! 
1661+ Fin de la segunda jornada M1 Omitido en E1 S1 S2 S3.

1661+ Tocan cajas y clarines y sale Cesarino E1 S2 S2 S3 Caja y clarines y sale Cesarino M1.

1665 Ver-

sos aña-

didos en

M1 Omi-

tido en $E 1$

S1 S2 S3

1702

1717

1739

1740

1746

1750

1755

1762

1763

1767

$1769+$

1827

1831

1832

1880

1905

1929

1954

1992

1996

1998

2002

2051
VOCES. Haced alto en el monte convecino
y solo Tacio y a Cesarino!

reprimido E1 S2 S3 M1 repremido E1 Errata.

alistan E1 S2 S3 M1 allistan S1 Errata.

anhelará E1 S2 S3 M1 añelará S1 Errata.

antiguo E1 S2 S3 M1 antigo S1 Errata.

anhela E1 S2 S3 M1 añela S1 Errata.

bizarría E1 S2 S3 M1 bizaría S1 Errata.

ha llegado E1 S1 S3 M1 haya llegado S2 Hipermetría.

de Roma ya E1 S2 S3 M1 de Roma S1.

por S1 S2 S3 M1 ppor S1 Errata.

desvío E1 S1 M1 desvelo S2 S3.

Tocan dentro y dicen E1 S1 S2 S3 Clarín y voz M1.

según eso E1 S2 S3 M1 según esto $S 1$.

anhelo E1 S2 S3 M1 añelo S1 Errata.

arroyuelo E1 S2 S3 arroyelo S1 Errata aroyuelo M1.

bandida E1 S1 M1 vendida S2 S3.

a la que heló el desmayo E1 S2 S3 M1 a la que él o el desmayo S1.

halagos E1 S1 alhagos S2 S3.

prueba E1 S2 S3 puueuan S1 Errata.

halago E1 S1 M1 alhago S2 S3.

que el volver S2 S3 M1 u que el volver E1 aquel boluer S1.

despreciando E1 S2 S3 M1 desdreciando S1 Errata.

a los halagos E1 S1 M1 a los alhagos S2 S3.

enemiga E1 S2 S3 M1 inimiga S1 Errata. 
2093+ Vanse y tocan chirimías y cajas y salen los músicos y Rómulo, Ostilio, Fabio, Ascanio y Aurelio, Libia y Auristela, y todas las mujeres de gala E1 S1 S2 S3 Vanse, tocan chirimías y salen los músicos de dos en dos y galanes en trajes diferentes y Rómulo y con la música forman un sarao M1.

2105 halagadme E1 S1 M1 alhagadme S2 S3.

2133 ayer E1 S2 S3 M1 a ver S1 Errata.

2135 a él E1 S2 S3 M1 a er S1 Errata.

2145 traía S1 S2 S3 M1 ttraía E1 Errata.

2149 ha prometido E1 S2 S3 M1 ha ptomedio S2 Errata.

2169 serena E1 S2 S3 M1 sereno S1.

2181 sucesiva E1 S2 S3 succesiva S3 M1 Errata.

2187 mientras E1 S2 S3 M1 mietnras S1 Errata.

2202 llega a hablarla, hablala en mi E1 S3 M1 llega a hablarla, habla en mí S1 S2.

2214 es inmenso E1 S1 M1 es immenso S2 S3.

2243 no ha estado E1 S1 M1 ha estado S2 S3.

2250 viuda E1 S2 S3 M1 linda S1.

2251 decillo E1 S1 S3 M1 decirlo S2.

2254 sufrillo E1 S1 S3 M1 sufrirlo S2.

2290 permití E1 permite S2 S3 M1 premití S1 Errata.

2315 ahora E1 S2 agora S1 S3 M1.

2328 dices de Cesarino E1 S3 M1 dices Cesarino S1 Hipometría.

2329 que anda S2 S3 que ha ando E1 S1 que ha andado M1.

2339 la señal S2 M1 la seña E1 S1 S3. Errata, porque rompe la métrica de la redondilla.

2354+ $\quad$ con E1 S2 S3 M1 odd S1 Errata.

2354+ $\quad$ pudieren E1 S2 S3 pudie- S1 Errata Omitido en M1.

2357+ Estando en la fuga del sarao tocan clarines y cajas y dice Rómulo E1 S1 S2 S3 Tocan cajas y clarines M1.

2359+ Dentro Cesarino E1 S1 S2 S3 Vanse todos y dentro Cesarino M1. 2360 mataldos E1 S1 matadlos S2 S3 M1.

2370 algún modo E1 S2 S3 M1 algum modo S1 Errata. 
2384+ Sale Cesarino E1 S1 S2 S3 Sale Cesarino y los suyos M1.

2387+ Sale Rómulo y los romanos por otra parte E1 S1 S2 S3 Sale Rómulo y los suyos M1.

2407+ Sale Auristela con la misma mascarilla del sarao puesta E1 S1 S2 S3 Sale Auristela con mascarilla M1.

2410+ Descúbrese Auristela E1 S1 S2 S3 Descúbrese M1.

2440 habrá si yo E1 S2 S3 M1 habrá S1.

2465 dejas E1 S1 S2 M1 dejes S3.

2475 molellas E1 S2 S3 M1 modellas S1 Errata.

2480 tan vil y infame E1 S1 M1 tan vil e infame S2 S3.

2486 asunto E1 S1 asumpto S2 S3 M1.

2495 previlegian E1 S1 S3 M1 privilegian S2.

2507 intentas E1 S2 S3 M1 inrentas S1 Errata.

2515 mejora E1 S2 S3 M1 mejorada S1 Errata.

2523+ Fin E1 Empieza el entremés de las Burlas del Doctor Juan Rana en las Fiestas del Retiro de Don Pedro Rosete S1 Fin. Con licencia: En Sevilla, por Manuel Nicolás Vázquez, en calle de Génova, donde se hallará todo surtido de comedias, corregidas fielmente por sus legítimos originales, entremeses, relaciones y romances S2 Fin. Hallarase esta comedia y otras de diferentes títulos en Madrid en la Imprenta de Antonio Sanz en la Plazuela de la Calle de la Paz. Año de 1754 S3. 